\title{
Development of Liquid Chromatography - UV Method for Simultaneous Determination of Leflunomide and NSAIDs in API and Pharmaceutical Formulations: It's Application to In vitro Interaction Studies
}

\section{Najma Sultana ${ }^{1}$, Mohammed Saeed Arayne ${ }^{2 *}$, Moona Mehboob Khan ${ }^{1}$ and Saeeda Nadir Ali ${ }^{2}$}

${ }^{1}$ Research Institute of Pharmaceutical Sciences, Department of Pharmaceutical Chemistry, University of Karachi, Karachi 75270, Pakisthan ${ }^{2}$ Department of Chemistry, University of Karachi, Karachi 75270, Pakisthan

\begin{abstract}
An efficient analytical method for the simultaneous determination of leflunomide and non steroidal anti-inflammatory drugs in API and formulations by LC-UV has been developed. The analytes were separated on Purospher Star, $\mathrm{C}_{18}(5$ $\mu \mathrm{m}, 250 \times 4.6 \mathrm{~mm})$ column at ambient temperature with methanol: water $(80: 20, \mathrm{v} / \mathrm{v}, \mathrm{pH}$ at 2.7$)$ at flow rate of $1.5 \mathrm{~mL}$ $\mathrm{min}^{-1}$. Experiment was conducted in two phases. Leflunomide was separated with flurbiprofen and ibuprofen (phaseI) and diclofenac sodium and mefenamic acid (phase II). Calibration curves were linear over the range $0.625-5 \mu \mathrm{g}$ $\mathrm{mL}^{-1}$ in both phases for leflunomide while for flurbiprofen, ibuprofen, diclofenac sodium, mefenamic acid linearity were achieved in the range of $0.625-5,11.25-90,1.56-50$ and $0.78-25 \mu \mathrm{g} \mathrm{mL}-1$, respectively with $r^{2}>0.9998$. Intraday variation was $<1.2$ and $<1.4 \%$, while in inter-day ranged between $0.042-1.45 \%$ and $0.08-1.27 \%$ in phase-I and II, respectively. Mean recovery values for intra-day ranged from $99.04-100.4 \%$ and $98.48-100.2 \%$ and for inter-day were between $98.54-100.29 \%$ and $98.85-100.54 \%$ in phase-I and II, respectively. The LLOD of leflunomide was 13 $\mathrm{ng} \mathrm{mL} \mathrm{m}^{-1}$, while LLOQ was $39 \mathrm{ng} \mathrm{mL}^{-1}$, respectively. LLOD and LLOQ for flurbiprofen, ibuprofen, diclofenac sodium and mefenamic acid were 6.9, 296, 71 and $1.2 \mathrm{ng} \mathrm{mL}^{-1}$ and $21,897,214.3$ and $3.676 \mathrm{ng} \mathrm{mL}^{-1}$, respectively. Present study showed that nanogram quantities of all the compounds can be estimated accurately. The newly established method was successfully applied to study in vitro interactions between leflunomide and NSAIDs.
\end{abstract}

Keywords: Leflunomide; Ibuprofen; Flurbiprofen; Diclofenac sodium, Mefenamic acid; HPLC; Interaction

\section{Introduction}

Leflunomide (Figure 1), 5-methyl- $N$-[4-(trifluoromethyl) phenyl]isoxazole-4-carboxamide is a leading disease modifying anti-rheumatic drug (DMARD) to treat rheumatoid arthritis (RA) [1]. Leflunomide and the malononitriloamides (MNA) are a new class of immunomodulating drugs that have been investigated for use in transplantation. Antiinflammatory and immunomodulating properties of leflunomide were recognized in 1985, which differ from classical anti-inflammatory and immunosuppressive drugs. Leflunomide has a long half-life (11 to 16 d) in humans, and because of this its clinical development has been restricted to use in patients of rheumatoid arthritis [2].

In phase II and III clinical trials of active rheumatoid arthritis, leflunomide was shown to improve primary and secondary outcome

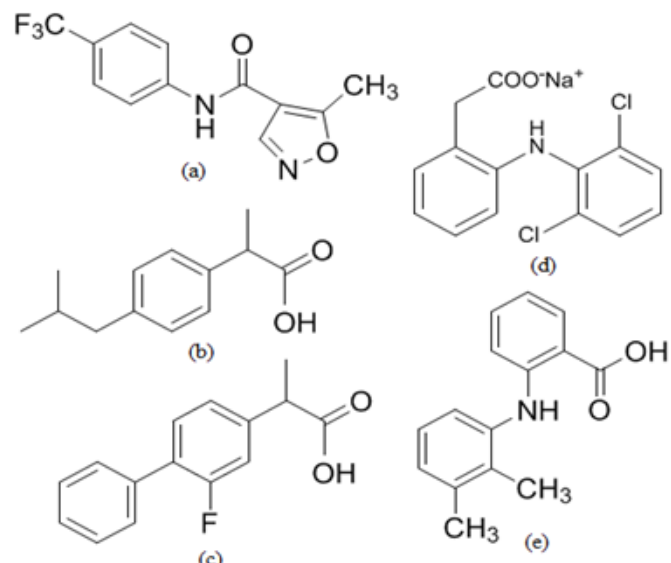

Figure 1: Chemical structures of (a) leflunomide, (b) flurbiprofen (c) ibuprofen, (d) diclofenac sodium and (e) mefenamic acid. measures with a satisfactory safety profile. The active metabolite of leflunomide, A77 1726, at low, therapeutically applicable doses, reversibly inhibits dihydroorotate dehydrogenase (DHODH), the rate limiting step in the de novo synthesis of pyrimidines. Continuing research indicates that A77 1726 may down regulate the glycosylation of adhesion molecules, effectively reducing cell-cell contact activation during inflammation [3]. It inhibits T-lymphocyte proliferation after converting to its active metabolite i.e. A771726 in human to produce its anti-arthritic action [4-6].

Leflunomide is a prodrug that is rapidly converted in the gastrointestinal tract and plasma to its active, open ring metabolite, the malononitrilamide, A771726 (2-cyano- 3-hydroxy- $\mathrm{N}$-(4trifluoromethylphenyl) butenamide). Structure-activity studies have shown how modifications to A771726 affect its immunoregulatory activity [7-9]. This drug along with NSAIDs (prostaglandin inhibitors) is used in the initial stages of remedy within three months of diagnosis to eradicate or diminish soreness, irritation, joint damage and to sustain normal function in RA patient $[10,11]$.

As leflunomide and NSAIDs are commonly prescribed in combination, the objective of this study was to establish an efficient, reliable, accurate and sensitive method for their simultaneous separation and quantification. Previously, numerous methods were developed

*Corresponding author: Mohammed Saeed Arayne, Department of Chemistry, University of Karachi, Karachi 75270, Pakisthan, E-mail: araynezs@gmail.com

Received June 29, 2013; Accepted September 12, 2013; Published September 15,2013

Citation: Sultana N, Arayne MS, Khan MM, Ali SN (2013) Development of Liquid Chromatography-UV Method for Simultaneous Determination of Leflunomide and NSAIDs in API and Pharmaceutical Formulations: It's Application to In vitro Interaction Studies. Med chem 3: 262-270. doi:10.4172/2161-0444.1000149

Copyright: $\odot 2013$ Sultana N, et al. This is an open-access article distributed under the terms of the Creative Commons Attribution License, which permits unrestricted use, distribution, and reproduction in any medium, provided the original author and source are credited. 
Citation: Sultana N, Arayne MS, Khan MM, Ali SN (2013) Development of Liquid Chromatography-UV Method for Simultaneous Determination of Leflunomide and NSAIDs in API and Pharmaceutical Formulations: It's Application to In vitro Interaction Studies. Med chem 3: $262-270$. doi:10.4172/2161-0444.1000149

and validated for leflunomide determination and quantification in IP, dosage formulations [12,13] and serum [14-16]. We have reported determination of lefunomide by RP-HPLC [17]. A method of reversed phase chromatography has been reported to separate seven NSAIDs i.e. naproxen, ketoprofen, ibuprofen, diclofenac, piroxicam, nimesulide and paracetamol using benzoic acid as an internal standard. Detection was made by two detectors, one by UV where compounds were detected at $245 \mathrm{~nm}$ and another by electrospray-mass spectroscopy where except paracetamol all NSAIDs were detected by negative ionization mode. Experiment was conducted by isocratic mode using acetonitrile-water with $0.1 \%$ acetic acid as the mobile phase [18].

A number of methods for the simultaneous determination of coadminstered drugs have also been reported by our research group as simultaneous determination of rosuvastatin, lisinopril, captopril and enalapril [19], lisinopril, [20] verapamil [21], captopril [22], ceftriaxone sodium [23], diltiazem [24] rosuvastatin [25] and sparfloxacin [26] with NSAIDs in API, pharmaceutical formulations and human serum by RPHPLC. Arayne et al. [27-34] and Sultana et al. [35-40] have previously reported, a number of methods for drug-drug interaction studies using UV-visible spectroscopic and RP-HPLC. In continuation of this work we have attempted to study in vitro interactions of leflunomide with flurbiprofen, ibuprofen, diclofenac sodium and mefenamic acid (Figure 1), the experiment was accomplished by the use of UV-visible spectroscopic and RP-HPLC techniques. For this purpose, interactions were studied at human environmental conditions $\mathrm{pH} 4$ and 9 where maximum quantity of leflunomide remains in its original form, while at $\mathrm{pH} 7.4$ (pH of the blood), its metabolite form, malononitrilamide, A77 1726 (2-cyano-3-hydroxy- $N$-(4-trifluoromethylphenyl) butenamide) is present in maximum concentration [4]. No liquid chromatographic method has yet been reported for separation and simultaneous analysis of leflunomide along with more than one NSAID although these drugs are co-administered simultaneously, so we have developed a simple, reliable, accurate, sensitive, cost effective and least time consuming method suitable for the simultaneous analysis of leflunomide and NSAIDs in API and pharmaceutical formulations. This method has been applied successfully to interaction studies of leflunomide with NSAIDs.

\section{Experimental}

\section{Materials}

Leflunomide (reference standard) was a gift from Hilton Pharma, reference standards of all the NSAIDs were supplied by Lab-9 of the Department of Chemistry, University of Karachi. Pharmaceutical formulations lefunomide (Lefora $10 \mathrm{mg}, 20 \mathrm{mg}$ ), flurbiprofen (Synalgo $100 \mathrm{mg}$ ), ibuprofen (Dolofen $200 \mathrm{mg}$ tablet), diclofenac sodium (Voltral' $50 \mathrm{mg}$ ) of Novartis Pharma and mefenamic acid (Ponstan 250 mg) of Parke-Davis \& Co Ltd were purchased from local Pharmacy. Each product was labeled and expiry date not earlier than two years, at the time of these studies.

All reagents were of HPLC grade. Methanol and phosphoric acid (85\%) (Merck, Germany) and HPLC-grade. Ultra-purified filtered water was used to prepare the mobile phase $(80: 20(\mathrm{v} / \mathrm{v})$ methanolwater).

\section{Chromatographic conditions}

The apparatus used for analysis consisted of Shimadzu model LC10AT VP pump with a SPD-10AT VP, variable wavelength UV-visible detector and chromatographic system was integrated via Shimadzu model CBM-102 Communication Bus Module. Simultaneous determination of leflunomide with NSAIDs was conducted in two phases. In the phase-I, leflunomide was simultaneously determined and validated with flurbiprofen and ibuprofen and in phase-II, it was determined along with diclofenac sodium and mefenamic acid. In both phases analysis were carried out by using methanol-water $(80: 20 \mathrm{v} / \mathrm{v})$ at pH 2.7 on Hiber, RT 250-4.6 Purospher Star RP-18 endcapped $(5 \mu \mathrm{m})$ column at flow rate $1.5 \mathrm{mLmin}^{-1}$. Detection was made at $254 \mathrm{~nm}$. Before delivering into the system, it was filtered through a $0.45 \mu \mathrm{m}$ millipore filter and degassed in an ultrasonic bath. The sample volume of $10 \mu \mathrm{L}$ was injected through a rheodyne injector valve into HPLC system.

\section{General procedure}

Stock solutions of leflunomide and NSAIDs were prepared by dissolving the drugs in methanol to yield concentration of $100 \mu \mathrm{g}$ $\mathrm{mL}^{-1}$ These solutions were prepared once and stored at $4^{\circ} \mathrm{C}$ protected from light. Calibration standards were prepared by diluting the stock solutions in the range of $0.625-5 \mu \mathrm{g} \mathrm{mL}^{-1}$ for both phases for leflunomide while for flurbiprofen, ibuprofen, diclofenac sodium, mefenamic acid solutions were diluted in the range $0.625-5,11.25-90,1.56-50$ and 0.78 $25 \mu \mathrm{g} \mathrm{mL}^{-1}$, respectively. $20 \mu \mathrm{L}$ of these solutions were injected into the LC system $(n=5)$. Before analysis, all the solutions were filtered through a $0.45 \mu \mathrm{m}$ vacuumed filter and degassed by sonicator.

\section{Analysis of pharmaceutical formulation}

Ten tablets of each formulation were separately powdered and amount equivalent to $10 \mathrm{mg}$ of leflunomide, flurbiprofen, ibuprofen, diclofenac sodium and mefenamic acid were dissolved in mobile phase in separate $100 \mathrm{~mL}$ volumetric flasks. The solutions were subjected to vigorous shaking and then allowed to stand for $1 \mathrm{~h}$ with intermittent sonication for complete extraction of the drug. All the solutions were then filtered and volume was brought to mark with mobile phase and then treated as above.

\section{Procedure for lefunomide-NSAIDs interactions}

In this phase of experiments, stock solutions $\left(100 \mu \mathrm{gmL}^{-1}\right)$ of leflunomide and interacting NSAIDs (flurbiprofen, ibuprofen diclofenac sodium and mefenamic acid were prepared in buffers of $\mathrm{pH} 4 \mathrm{(pH}$ of full stomach) and $\mathrm{pH} 9$ (simulated intestinal juice) individually. These two $\mathrm{pH}$ were selected for studying leflunomide in vitro interactions because at theses $\mathrm{pH}$, leflunomide remains in its original form, while at $\mathrm{pH} 7.4$ (pH of the blood), its metabolite, malononitrilamide, A77 1726 (2-cyano-3-hydroxy- $N$-(4-trifluoromethylphenyl) butenamide) is present in maximum concentration [5,6]. In case of leflunomide, first it was dissolved in minimum quantity of methanol and then diluted by buffer of $\mathrm{pH} 4$ and $\mathrm{pH} 9$ individually. These solutions were mixed in equimolar ratios in Erlenmeyer flasks and refluxed at $37 \pm$ $5^{\circ} \mathrm{C}$ for two hours. An aliquot of $5 \mathrm{~mL}$ was withdrawn after every 30 minutes interval for two hours. After appropriate dilutions, aliquots were filtered via $0.45 \mu$ filter paper and analyzed by RP- HPLC method. Concentration of each drug was determined using linear equation and percentage availability was calculated. The data was analyzed by student $\mathrm{t}$-test using $\mathrm{p}<0.05$ as significant value.

The above aliquots of interacting drugs were also analyzed by using UV-spectrophotometer and data was also analyzed by student t-test using $\mathrm{p}<0.05$ as significant value.

\section{Results and Discussion}

\section{Optimization of the chromatographic conditions}

RP-HPLC is a high-ranking tool for drug analysis; the advantages of short retention time, method reliability, sensitivity and drug specificity substantiate the use of HPLC for various groups of drugs. Therefore the 
Citation: Sultana N, Arayne MS, Khan MM, Ali SN (2013) Development of Liquid Chromatography-UV Method for Simultaneous Determination of Leflunomide and NSAIDs in API and Pharmaceutical Formulations: It's Application to In vitro Interaction Studies. Med chem 3: $262-270$. doi:10.4172/2161-0444.1000149

main objective of this study was to develop a simple, easy and effectual liquid chromatographic method with UV detection for simultaneous analysis of leflunomide and NSAIDs in bulk drug and pharmaceutical formulations. Initially $\mathrm{C}_{18}$ Discovery column $(125 \mathrm{~cm} \times 4.6 \mathrm{~mm}, 5$ $\mu \mathrm{m}$ particle) and Phouspher Start $(5 \mu \mathrm{m}, 12.5 \times 0.46 \mathrm{~mm})$ analytical reverse-phased column were used for separation of leflunomide and NSAIDs. Due to poor resolution and high retention time (more than 15 minutes), these columns were not selected for this work. Use of Hiber, RT 250-4.6 Purospher Star RP-18 end capped ( $5 \mu \mathrm{m})$ column produced good symmetrical peaks with high resolution and short retention time.

In case of solvent selection, isocratic mode was applied for elution instead of gradient to avoid re-equilibration [24]. Initially, method was optimized by varying methanol: water ratios $(80: 20,85: 15 \mathrm{v} / \mathrm{v})$ at various $\mathrm{pH}(3.4,3.2,2.9,2.7)$ and flow rates $\left(0.8 \mathrm{~mL} \cdot \mathrm{min}^{-1}, 1.2 \mathrm{~mL} \cdot \mathrm{min}^{-1}, 1.5\right.$ $\mathrm{ml} \mathrm{min}^{-1}$ ) which lead to considerable changes in the chromatographic parameters, like peak symmetry, drug resolutions and retention time. However, the ratio of methanol: water in 80:20 (v/v) with flow rate 1.5 ml. $\mathrm{min}^{-1}$ at $\mathrm{pH} 2.7$ at $254 \mathrm{~nm}$ yielded best results. It had been observed (Figures $2 \mathrm{a}$ and $2 \mathrm{~b}$ ) that drugs were best separated and gave wellshaped narrow peaks at low $\mathrm{pH}$ and selected flow rates. Alteration in both parameters also affected the retention times for all drugs while excellent result was achieved at $\mathrm{pH} 2.7 \pm 0.2$ keeping flow rate $1.5 \pm$ $0.2 \mathrm{~mL} \cdot \mathrm{min}^{-1}$.

\section{Peak identification}

Under optimized conditions, the peaks of leflunomide and mentioned NSAIDs were identified by comparing chromatograph of leflunomide and NSAIDs standards with the chromatograph of their tablets (Figures 2a and 2b). Under described chromatographic conditions, in phase-I, leflunomide, flurbiprofen and ibuprofen were eluted with retention times of 2.9, 3.37 and 3.8 minutes, respectively while in phase -II leflunomide, diclofenac sodium and mefenamic acid were eluted with retention times of $2.9,3.6$ and 4.9 minutes, respectively.

\section{Validation}

Importance of validation for a developed method to check its suitability for intended purpose holds prime position. The developed method was validated according to ICH guidelines [25] and USP 2002 [26]. It includes various parameters as system suitability, selectivity, specificity, linearity, accuracy, precision (robustness and ruggedness) and sensitivity which were followed to validate the method.

\section{System suitability}

To assure the appropriate work of the method during whole analysis,
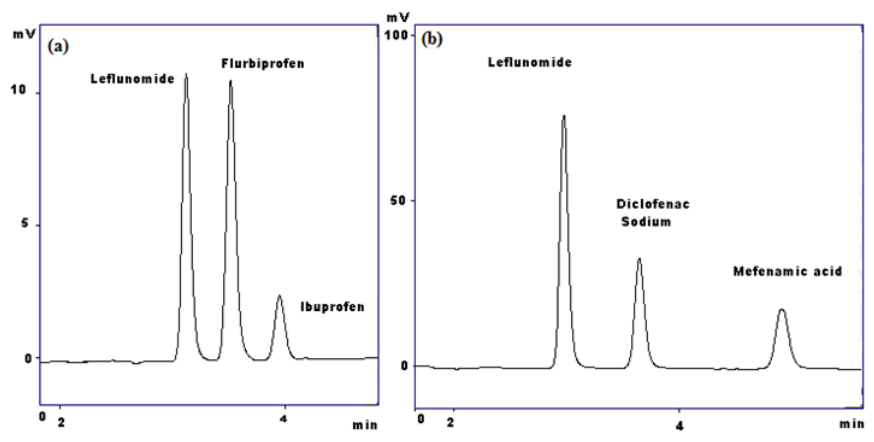

Figure 2: (a) Phase-I Leflunomide (2.9 min) chromatogram with flurbiprofen (3.37 $\mathrm{min})$ and ibuprofen (3.8 $\mathrm{min})$ and (b) Phase-II. Leflunomide (2.9 min) chromatogram with diclofenac sodium (3.6 min) and mefenamic acid (4.9 $\min )$. system suitability were checked by injecting six replicates of each drug standard solutions and appraisal was made by analyzing repeatability, relative retention, column efficiency (number of theoretical plate), capacity factor and symmetry factor as indicated in Table 1.

\section{Linearity}

For linearity, linear regression analysis was performed using Microsoft Excel 2003 software. Calibration curves were found to be linear over the range of $0.625-5 \mu \mathrm{g} \mathrm{mL}^{-1}$ in both phases for leflunomide while for flurbiprofen, ibuprofen, diclofenac sodium, mefenamic acid linearity were achieved in the range $0.625-5,11.25-90,1.56-50$ and 0.78 $25 \mu \mathrm{g} \mathrm{mL}{ }^{-1}$, respectively with correlation coefficients $\left(r^{2}\right)$ of $>0.9998$ (Table 2). For leflunomide, minimum limit of analyte that the method can detect i.e. detection limits (LLOD) was calculated by the formula $\mathrm{LLOD}=3.3 \mathrm{SD} /$ slope and in pharmaceutical formulation it was found $13 \mathrm{ng} \mathrm{mL} \mathrm{mL}^{-1}$, respectively. Quantification limit (LLOQ) was evaluated as ten times the noise level (LLOD=10 SD/ slope) and were found as $39 \mathrm{ng} \mathrm{mL}^{-1}$, respectively. LLOD and LLOQ for flurbiprofen, ibuprofen, diclofenac sodium and mefenamic acid were 6.9, 296, 71 and $1.2 \mathrm{ng}$ $\mathrm{mL}^{-1}$ and $21,897,214.3$ and $3.676 \mathrm{ng} \mathrm{mL}^{-1}$, respectively, suggesting that nanogram quantities of all the compounds can be estimated accurately (Table 3).

\section{Precision and accuracy}

For precision intra-day (repeatability) and inter-day (reproducibility) analysis were performed which are expressed as the coefficient of variation ( $\mathrm{RSD}=$ standard deviation/mean ${ }^{\star} 100$ ). $\% \mathrm{RSD}$ is a useful parameter to compare uncertainty between different measurements of varying absolute magnitude. For this purpose six concentrations $(n=6)$ of each drug in the linear range were analyzed on the same day (intra-day precision) and two consecutive days (interday precision). Accuracy of the method was determined as percentage recovery of known amount of these drugs in their dosage solution. Intra-day \% RSD values of the measurements of all analytes ranged between $0.17-1.15 \%$ in phase-I while $0.02-1.35 \%$ in phase-II while in inter-day \% RSD ranged between $0.042-1.45 \%$ in phase-I and $0.08-1.27 \%$ in phase-II. The mean recovery values for intra-day were 99.04-100.4\% in phase-I and $98.48-100.2 \%$ in phase-II while for interday ranged between $98.54-100.29 \%$ in phase-I and $98.85-100.54 \%$ in phase-II, as indicated in Table 2.

\section{Selectivity and sensitivity}

This method was selective and sensitive. In the representative chromatograms (Figures $3 \mathrm{a}$ and $3 \mathrm{~b}$ ) of the drugs in formulation there was no extra peak reflecting no interference of excipients present.

\section{Stability}

The stability of standard and sample solutions of leflunomide was evaluated by assay after $24 \mathrm{~h}$ at $4^{\circ} \mathrm{C}$ against fresh standard solutions, which showed that leflunomide was stable and did not show significant variations in the time span of 24 hours.

\section{Ruggedness}

Method ruggedness was performed by two analysts on separate lots of leflunomide. Each analyst prepared samples in triplicate and used separate instruments, reagents and mobile phase solutions. \% RSD $(n=5)$ for all of the samples for each lot was less than $3.5 \%$ and method did not show any notable deviation in results from acceptable limits.

\section{Robustness}

Deliberate changes were made by altering the flow rate, $\mathrm{pH}$ and 
Citation: Sultana N, Arayne MS, Khan MM, Ali SN (2013) Development of Liquid Chromatography-UV Method for Simultaneous Determination of Leflunomide and NSAIDs in API and Pharmaceutical Formulations: It's Application to In vitro Interaction Studies. Med chem 3: $262-270$. doi:10.4172/2161-0444.1000149

\begin{tabular}{|c|c|c|c|c|c|c|}
\hline Analytes & Retention time $\left(T_{R}\right)$ (min) & Capacity factor (K') & Theoretical plates (N) & Tailing factor (T) & Resolution (R) & Separation factor $(\alpha)$ \\
\hline \multicolumn{7}{|c|}{ pH $2.7 \pm 0.05$} \\
\hline \multicolumn{7}{|c|}{ Phase-1 } \\
\hline Lef & $2.9 \pm 0.024$ & $0.54 \pm 0.013$ & $7182 \pm 0.58 .2$ & $1.26 \pm 0.09$ & $1.26 \pm 0.14$ & $2.68 \pm 0.06$ \\
\hline Flur & $3.37 \pm 0.21$ & $0.75 \pm 0.101$ & $7606 \pm 0.37 .9$ & $1.18 \pm 0.093$ & $1.18 \pm 0.07$ & $1.37 \pm 0.13$ \\
\hline Ibu & $3.8 \pm 0.18$ & $0.96 \pm 0.021$ & $9769 \pm 53.1$ & $1.17 \pm 0.17$ & $1.17 \pm 0.10$ & $1.29 \pm 0.21$ \\
\hline \multicolumn{7}{|l|}{ Phase-2 } \\
\hline Lef & $2.9 \pm 0.08$ & $0.41 \pm 0.051$ & $7229 \pm 53$ & $1.21 \pm 0.11$ & $1.21 \pm 0.15$ & $3.9 \pm 0.15$ \\
\hline Diclo & $3.6 \pm 0.23$ & $0.73 \pm 0.019$ & $7735 \pm 78$ & $1.15 \pm 0.07$ & $1.15 \pm 0.084$ & $1.78 \pm 0.05$ \\
\hline Mef & $4.9 \pm 0.15$ & $1.34 \pm 0.09$ & $8629 \pm 23$ & $1.14 \pm 0.13$ & $1.14 \pm 0.17$ & $1.82 \pm 0.29$ \\
\hline \multicolumn{7}{|c|}{ Flow rate $1.5 \pm 0.2$} \\
\hline \multicolumn{7}{|c|}{ Phase-1 } \\
\hline Lef & $2.91 \pm 0.13$ & $0.54 \pm 0.08$ & $7181 \pm 67$ & $1.25 \pm 0.13$ & $1.262 \pm 0.05$ & $2.68 \pm 0.21$ \\
\hline Flur & $3.367 \pm 0.16$ & $0.75 \pm 0.051$ & $7619 \pm 25$ & $1.182 \pm 0.07$ & $1.19 \pm 0.12$ & $1.37 \pm 0.07$ \\
\hline lbu & $3.81 \pm 0.25$ & $0.96 \pm 0.13$ & $9771 \pm 89$ & $1.20 \pm 0.15$ & $1.16 \pm 0.11$ & $1.29 \pm 0.061$ \\
\hline \multicolumn{7}{|l|}{ Phase-2 } \\
\hline Lef & $2.9 \pm 0.13$ & $0.41 \pm 0.087$ & $7230 \pm 33$ & $1.21 \pm 0.16$ & $1.21 \pm 0.18$ & $3.9 \pm 0.22$ \\
\hline Diclo & $3.6 \pm 0.098$ & $0.73 \pm 0.12$ & $7743 \pm 27$ & $1.15 \pm 0.59$ & $1.15 \pm 0.12$ & $1.78 \pm 0.09$ \\
\hline Mef & $4.9 \pm 0.14$ & $1.34 \pm 0.21$ & $8631 \pm 76$ & $1.14 \pm 0.2$ & $1.14 \pm 0.19$ & $1.82 \pm 0.13$ \\
\hline \multicolumn{7}{|c|}{ Methanol percentage $80 \pm 2 \%$} \\
\hline \multicolumn{7}{|c|}{ Phase-1 } \\
\hline Lef & $2.89 \pm 0.21$ & $0.539 \pm 0.07$ & $7183 \pm 83$ & $1.26 \pm 0.06$ & $1.21 \pm 0.051$ & $2.66 \pm 0.08$ \\
\hline Flur & $3.36 \pm 0.31$ & $0.752 \pm 0.052$ & $7616 \pm 34$ & $1.18 \pm 0.09$ & $1.15 \pm 0.21$ & $1.37 \pm 0.31$ \\
\hline Ibu & $3.81 \pm 0.09$ & $0.95 \pm 0.12$ & $9760 \pm 67$ & $1.17 \pm 0.14$ & $1.14 \pm 0.17$ & $1.30 \pm 0.16$ \\
\hline \multicolumn{7}{|l|}{ Phase-2 } \\
\hline Lef & $2.91 \pm 0.19$ & $0.41 \pm 0.05$ & $7243 \pm 49$ & $1.21 \pm 0.11$ & $1.20 \pm 0.08$ & $3.9 \pm 0.07$ \\
\hline Diclo & $3.56 \pm 0.22$ & $0.73 \pm 0.061$ & $7727 \pm 33$ & $1.15 \pm 0.097$ & $1.14 \pm 0.019$ & $1.78 \pm 0.25$ \\
\hline Mef & $4.89 \pm 0.071$ & $1.34 \pm 0.074$ & $8632 \pm 92$ & $1.14 \pm 0.13$ & $1.21 \pm 0.13$ & $1.82 \pm 0.31$ \\
\hline
\end{tabular}

Lef=leflunomide, Flur=flurbiprofen, Ibu=ibuprofen, Mef=mefanamic acid, Diclo=diclofenac sodium. All data presented in mean \pm standard deviation ( $\mathrm{n}=6$ )

Table 1: System suitability and ruggedness of the developed method.

\begin{tabular}{|c|c|c|c|c|c|c|}
\hline \multirow{2}{*}{ Drugs } & \multirow{2}{*}{ Conc $\left(\mu \mathrm{g} \mathrm{mL}^{-1}\right)$} & \multicolumn{3}{|c|}{ Intraday precision } & \multicolumn{2}{|c|}{ Interday precision } \\
\hline & & \multicolumn{2}{|c|}{$\% \operatorname{Rec}$} & $\%$ RSD & $\% \operatorname{Rec}$ & $\%$ RSD \\
\hline \multicolumn{7}{|c|}{ Phase-1 } \\
\hline \multirow{5}{*}{ Lef } & 0.625 & & 99.88 & 0.168 & 99.57 & 0.102 \\
\hline & 1.25 & & 100.12 & 0.102 & 99.54 & 0.103 \\
\hline & 1.875 & & 99.85 & 1.15 & 99.9 & 0.85 \\
\hline & 2.5 & & 100.05 & 1.06 & 100.11 & 1.45 \\
\hline & 5 & & 99.19 & 1.14 & 99.66 & 0.74 \\
\hline \multirow{5}{*}{ Flur } & 0.625 & & 100.26 & 0.39 & 100.29 & 0.58 \\
\hline & 1.25 & & 100.07 & 0.53 & 100.04 & 0.39 \\
\hline & 1.875 & & 99.04 & 0.087 & 99.98 & 1.02 \\
\hline & 2.5 & & 100.01 & 0.192 & 99.94 & 0.042 \\
\hline & 5 & & 99.61 & 0.48 & 100.2 & 1.08 \\
\hline \multirow{5}{*}{ Ibu } & 11.25 & & 100.41 & 1.12 & 99.97 & 0.166 \\
\hline & 22.5 & & 100.02 & 1.02 & 98.54 & 0.32 \\
\hline & 33.75 & & 100.10 & 0.24 & 100.2 & 1.08 \\
\hline & 45 & & 99.76 & 0.29 & 99.89 & 0.33 \\
\hline & 90 & & 99.42 & 0.17 & 100.12 & 0.90 \\
\hline \multicolumn{7}{|c|}{ Phase-2 } \\
\hline \multirow{5}{*}{ Lef } & 0.625 & & 99.78 & 0.34 & 99.57 & 0.08 \\
\hline & 1.25 & & 99.88 & 0.06 & 99.54 & 0.27 \\
\hline & 1.875 & & 100.02 & 0.02 & 100.29 & 0.29 \\
\hline & 2.5 & & 99.57 & 0.03 & 100.18 & 0.87 \\
\hline & 5 & & 100.48 & 0.63 & 99.66 & 0.06 \\
\hline \multirow{5}{*}{ Diclo } & 1.56 & & 99.46 & 1.13 & 100.16 & 0.18 \\
\hline & 6.25 & & 100.21 & 0.26 & 99.87 & 0.29 \\
\hline & 12.5 & & 100.5 & 0.15 & 99.98 & 1.17 \\
\hline & 25 & & 98.78 & 0.66 & 100.2 & 0.68 \\
\hline & 50 & & 100.1 & 0.63 & 99.85 & 1.27 \\
\hline \multirow{5}{*}{ Mef } & 0.78 & & 98.78 & 0.28 & 100.1 & 0.015 \\
\hline & 3.125 & & 100.03 & 0.86 & 100.54 & 0.97 \\
\hline & 6.25 & & 100.18 & 1.35 & 98.98 & 0.016 \\
\hline & 12.5 & & 99.78 & 0.37 & 99.48 & 0.99 \\
\hline & 25 & & 98.48 & 0.14 & 100.2 & 0.43 \\
\hline
\end{tabular}

Table 2: Precision and recovery of leflunomide and NSAIDs. 
Citation: Sultana N, Arayne MS, Khan MM, Ali SN (2013) Development of Liquid Chromatography-UV Method for Simultaneous Determination of Leflunomide and NSAIDs in API and Pharmaceutical Formulations: It's Application to In vitro Interaction Studies. Med chem 3: $262-270$. doi:10.4172/2161-0444.1000149

\begin{tabular}{|c|c|c|c|c|}
\hline Drugs & Regression equation & R2 & LLOD ng mL-1 & LLOQ ng mL-1 \\
\hline \multicolumn{5}{|c|}{ Phase-1 } \\
\hline Lef & $y=11428 x+1345.6$ & 0.9998 & 13 & 39 \\
\hline Flur & $y=13149 x+118.64$ & 0.9998 & 6.9 & 21 \\
\hline lbu & $y=204.9 x-970.43$ & 0.9985 & 296 & 897 \\
\hline \multicolumn{5}{|c|}{ Phase-2 } \\
\hline Lef & $y=16783 x+7014.6$ & 0.998 & 13 & 39 \\
\hline Diclo & $y=4488.5 x-369.24$ & 0.9992 & 71 & 214.3 \\
\hline Mef & $y=2766.6 x+11798$ & 0.9985 & 1.2 & 3.676 \\
\hline
\end{tabular}

Lef=leflunomide, Flur=flurbiprofen, Ibu=ibuprofen, Mef=mefanamic acid,Diclo=diclofenac sodium $(n=6)$

Table 3: Sensitivity of the proposed methods.

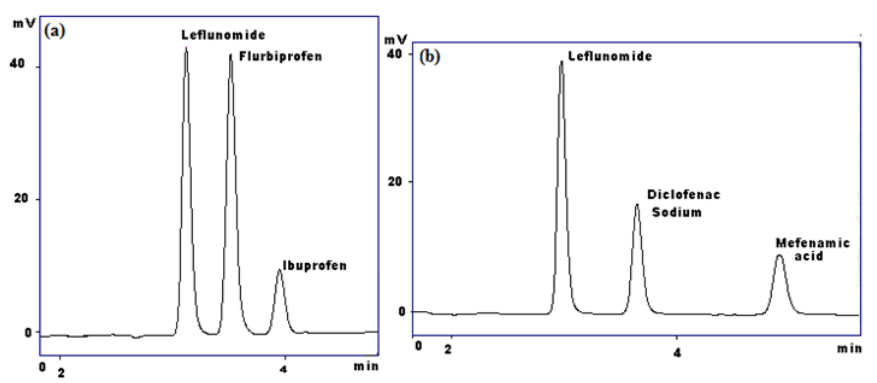

Figure 3: Representative chromatograms of (a) Phase-I Leflunomide with flurbiprofen and ibuprofen and (b) Phase-II. Leflunomide with diclofenac sodium and mefenamic acid in pharmaceutical formulations.

composition of the mobile phase to validate the robustness of the method. Data (Table 4) indicates that there was no significant variation while making these changes.

\section{Interaction studies of Lefunomide with NSAIDs by UV and HPLC techniques}

UV- spectrophotometer: The UV/visible spectra (zero-order) of leflunomide in presence of NSAIDs in buffers of $\mathrm{pH} 4$ and $\mathrm{pH}$ 9, indicates that simultaneous determination of leflunomide with NSAIDs by conventional UV spectroscopy is not possible. Therefore, first derivative spectra of leflunomide and the above interacting drugs, having zero-crossing points at $\mathrm{pH} 4$ (Figure 4a) and at $\mathrm{pH} 9$ (Figure $4 \mathrm{~b})$ were used for their simultaneous determination without any prior separation in mixtures.

The absorbance at zero crossing points of leflunomide and interacting NSAIDs were chosen for their simultaneous determination. By constructing standard calibration curves between first derivative values of these drugs versus their concentration, Beer's law was confirmed (Tables 5,6). Least-squares method was used to determine regression curves. The linear calibration regression function for the spectroscopic determination of analyte at selected wavelength is given by $y=m x+c$, where $y, m, x$ represents the absorbance, slope of linear regression and concentration of analyte (mMole), respectively while $c$ is the intercept value, which reflects the difference between ideal and the real system. Two equation sets were used for the measurement of binary mixtures at two selected wavelengths (Tables 5 and 6). The first derivative spectra showed the best linear response to analyte concentration used at these wavelengths.

After determining the concentration of leflunomide and interacting NSAIDs by their, respective equations (Tables 5 and 6), their percentage availability were calculated (Table 7 ). Data was analyzed by student t-test keeping $p<0.05$ significant and $p<0.005$ as highly significant.
On HPLC: The developed and validated RP-HPLC method was successfully applied to study in vitro interactions between leflunomide and above mentioned NSAIDs (Figures $5 \mathrm{a}$ and $5 \mathrm{~b}$ ). Concentration of each drug was determined using linear equation after every 30 minutes and percentage availability was calculated. Data was also analyzed by student t-test using $\mathrm{p}<0.05$ and $\mathrm{p}<0.005$ as significant and highly significant, respectively. These studies indicated that percentage availability of leflunomide with all mentioned NSAIDs became altered at $\mathrm{pH} 4$ and $\mathrm{pH} 9$ which can directly affect its efficacy. Similar situation was also faced by these mentioned NDAIDs. Student $\mathrm{t}$-test indicated that interaction of leflunomide with flurbiprofen (Table 8) became highly significant after 120 minutes at $\mathrm{pH} 4$. At $\mathrm{pH} 9$, this interaction was not as prominent as in case of $\mathrm{pH} 4$ where interaction turned to highly significant $(\mathrm{p}<0.005)$ after 150 minutes.

Similarly, student t-test also indicated that leflunomide interacts with ibuprofen at both $\mathrm{pH}$ in highly significant $(\mathrm{p}<0.005)$ manner after 150 minutes. Diclofenac sodium interacted with leflunomide significantly just within one hour of reaction at both $\mathrm{pH}$. This interaction became highly significant $(\mathrm{p}<0.005)$ within 60 minutes at $\mathrm{pH} 4$ but at $\mathrm{pH} 9$, reaction took 150 minutes to became highly significant. The potential interaction of leflunomide and mefenamic acid was studied only at $\mathrm{pH} 9$ because at $\mathrm{pH} 4$ this drug is insoluble. At $\mathrm{pH}$ 9, student $\mathrm{t}$-test indicated that during whole procedure the

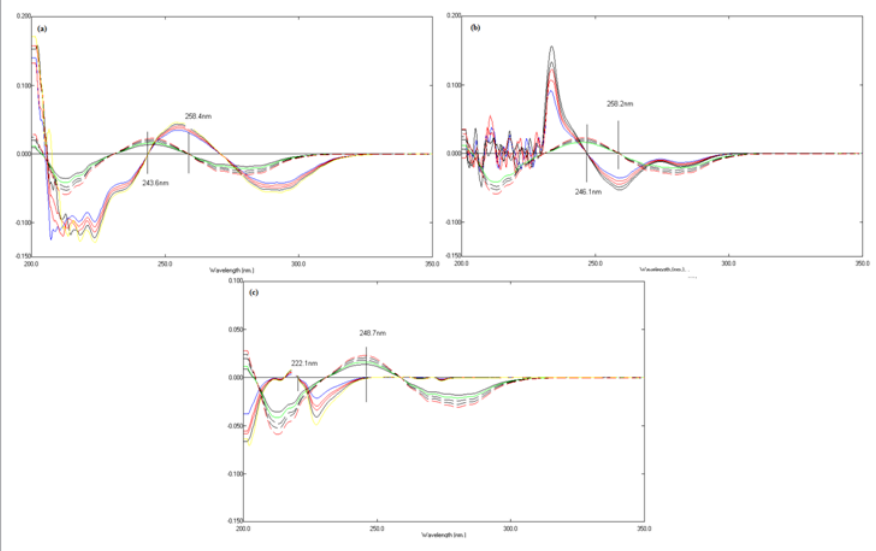

Figure 4a: First derivative UV spectra of leflunomide (in dotted line) and (a) diclofenac sodium (b) flurbiprofen and (c) ibuprofen at $\mathrm{pH} 4$.

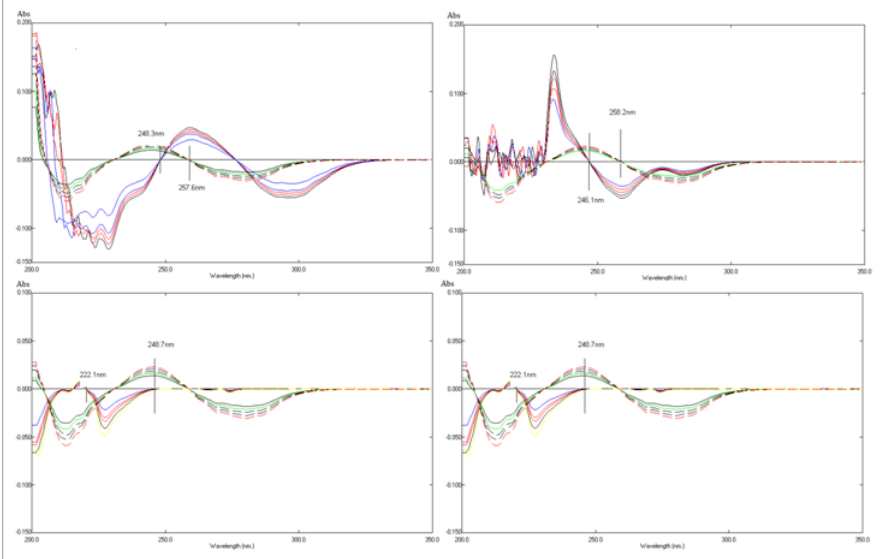

Figure 4b: First derivative UV spectra of leflunomide (in dotted line) and (a) diclofenac sodium (b) flurbiprofen and (c) ibuprofen and (d) mefenamic acid at $\mathrm{pH} 9$. 
Citation: Sultana N, Arayne MS, Khan MM, Ali SN (2013) Development of Liquid Chromatography-UV Method for Simultaneous Determination of Leflunomide and NSAIDs in API and Pharmaceutical Formulations: It's Application to In vitro Interaction Studies. Med chem 3: $262-270$. doi:10.4172/2161-0444.1000149

\begin{tabular}{|c|c|c|c|c|c|c|c|c|c|}
\hline \multirow{3}{*}{ Precision } & \multicolumn{9}{|c|}{ Factors changed } \\
\hline & \multicolumn{3}{|c|}{$\mathrm{pH} \pm 0.05$} & \multicolumn{3}{|c|}{ Flow rate $\left(\mathrm{ml} \mathrm{min}^{-1}\right) \pm 0.2$} & \multicolumn{3}{|c|}{ Methanol $\% \pm 0.2 \%$} \\
\hline & 2.65 & 2.7 & 2.75 & 1.45 & 1.5 & 1.55 & 79.8 & 80 & 80.2 \\
\hline Lef \%RSD & 0.62 & 0.78 & 0.65 & 0.99 & 0.78 & 0.39 & 0.23 & 0.78 & 0.73 \\
\hline Flur \%RSD & 0.079 & 0.534 & 1.04 & 0.78 & 0.534 & 0.25 & 0.62 & 0.534 & 0.96 \\
\hline lbu \%RSD & 0.58 & 0.166 & 0.35 & 0.056 & 0.166 & 0.87 & 1.02 & 0.166 & 1.03 \\
\hline Mef \%RSD & 0.742 & 0.016 & 1.05 & 0.044 & 0.016 & 1.08 & 0.029 & 0.016 & 0.57 \\
\hline Diclo \%RSD & 0.43 & 0.29 & 0.48 & 0.82 & 0.29 & 0.92 & 0.45 & 0.29 & 0.43 \\
\hline
\end{tabular}

Lef=leflunomide, Flur=flurbiprofen, Ibu=ibuprofen, Mef=mefanamic acid, Diclo=diclofenac sodium. $\mathrm{n}=6$

Table 4: \%RSD during robustness analysis.

\begin{tabular}{|c|c|c|c|c|c|}
\hline S. No & Drug & Wavelength (nm) & Linearity range (mMole) & Regression equation & Correlation coefficient \\
\hline \multirow{2}{*}{1} & Lef & 243.6 & $0.01-.055$ & $Y=0.457 x-6^{*} 10^{-5}$ & 0.9987 \\
\hline & Diclo & 258.4 & $0.09-0.18$ & $Y=0.244 x-6 * 10^{-5}$ & 0.9986 \\
\hline \multirow[t]{2}{*}{2} & Lef & 246.1 & $0.01-0.055$ & $Y=0.435 x+0.0011$ & 0.9987 \\
\hline & Flur & 258.2 & $0.06-0.15$ & $Y=0.442 x-0.008$ & 0.999 \\
\hline \multirow[t]{2}{*}{3} & Lef & 248.1 & $0.01-0.055$ & $Y=0.430 x-0.003$ & 0.9993 \\
\hline & Ibu & 231.4 & $0.01-0.08$ & $Y=0.615 x+-0.003$ & 0.9926 \\
\hline
\end{tabular}

Lef=leflunomide, Flur=flurbiprofen, Ibu=ibuprofen, Mef=mefanamic acid Diclo=diclofenac sodium

Table 5: Regression analysis of leflunomide and NSAIDs at $\mathrm{pH} 4$ by first order derivative spectrophotometry.

\begin{tabular}{|c|c|c|c|c|c|}
\hline S. No & Drug & Wavelength (nm) & Linearity range (mMole) & Regression equation & Correlation coefficient \\
\hline \multirow[t]{2}{*}{1} & Lef & 243.6 & $0.01-.055$ & $Y=0.429 x-4 E-05$ & 0.998 \\
\hline & Diclo & 258.4 & $0.09-0.18$ & $Y=0.294 x-0.001$ & 0.984 \\
\hline \multirow[t]{2}{*}{2} & Lef & 246.1 & $0.01-0.055$ & $Y=0.449 x+8 E-05$ & 0.995 \\
\hline & Flur & 258.2 & $0.06-0.15$ & $Y=0.440 x-0.002$ & 0.984 \\
\hline \multirow[t]{2}{*}{3} & Lef & 248.1 & $0.01-0.055$ & $Y=0.488 x-0.000$ & 0.983 \\
\hline & Ibu & 231.4 & $0.01-0.08$ & $Y=1.036 x+0.025$ & 0.995 \\
\hline \multirow{2}{*}{4} & Lef & 253.2 & $0.01-0.055$ & $Y=0.244 x+7 E-06$ & 0.997 \\
\hline & Mef & 231.4 & $0.02-0.065$ & $Y=1.561 x-0.023$ & 0.999 \\
\hline
\end{tabular}

Lef=leflunomide, Flur=flurbiprofen, Ibu=ibuprofen, Mef=mefanamic acid, Diclo=diclofenac sodium

Table 6: Regression analysis of leflunomide and NSAIDs at $\mathrm{pH} 9$ by first order derivative spectrophotometry.

\begin{tabular}{|c|c|c|c|c|}
\hline \multirow{2}{*}{ Time (min) } & \multicolumn{2}{|c|}{ At pH $4 \%$ Availability (mean \pm S.D) } & \multicolumn{2}{|c|}{ At pH $9 \%$ Availability(mean \pm S.D) } \\
\hline & Lef & Flur & Lef & Flur \\
\hline 0 & $100.35 \pm 0.98$ & $99.99 \pm 0.98$ & $100.1 \pm 0.42$ & $100.28 \pm 0.11$ \\
\hline 30 & $99.55 \pm 0.51$ & $98.45 \pm 0.25$ & $100.4 \pm 0.51$ & $100.1 \pm 0.25$ \\
\hline $60^{*}$ & $99.79 \pm 0.26$ & $105.47 \pm 0.50$ & $100.3 \pm 0.26$ & $99.89 \pm 0.51$ \\
\hline $90^{*}$ & $101.61 \pm 0.61$ & $109.58 \pm 0.52$ & $99.87 \pm 0.61$ & $98.78 \pm 0.52$ \\
\hline $120^{*}$ & $98.00 \pm 1.02$ & $109.43 \pm 0.40$ & $99.99 \pm 0.99$ & $99.15 \pm 0.45$ \\
\hline $150^{*+}$ & $94.24 \pm 1.54$ & $108.97 \pm 0.64$ & $102.1 \pm 1.08$ & $100.15 \pm 0.89$ \\
\hline \multirow[t]{2}{*}{$180^{* *+}$} & $100.55 \pm 0.31$ & $107.41 \pm 1.01$ & $103.75 \pm 0.51$ & $101.87 \pm 0.49$ \\
\hline & Lef & lbu & Lef & $\mathrm{Ibu}$ \\
\hline 0 & $100.22 \pm 0.98$ & $100.17 \pm 0.24$ & $100.7 \pm 0.71$ & $100.33 \pm 0.325$ \\
\hline 30 & $104.32 \pm 0.46$ & $103.97 \pm 0.35$ & $101.75 \pm 0.778$ & $101.23 \pm 0.478$ \\
\hline 60 & $107.56 \pm 0.45$ & $107.08 \pm 0.13$ & $101.65 \pm 0.212$ & $101.42 \pm 0.60$ \\
\hline $90^{*}$ & $108.54 \pm 0.41$ & $114.33 \pm 0.91$ & $101.2 \pm 1.23$ & $101.39 \pm 0.55$ \\
\hline $120^{*}$ & $105.32 \pm 0.32$ & $107.54 \pm 0.42$ & $102.225 \pm 0.38$ & $100.65 \pm 0.489$ \\
\hline $150^{\star *+}$ & $105.92 \pm 0.11$ & $108.29 \pm 0.53$ & $101.95 \pm 0.49$ & $99.93 \pm 0.98$ \\
\hline \multirow[t]{2}{*}{$180^{* *+}$} & $105.07 \pm 0.178$ & $117.87 \pm 0.19$ & $102.35 \pm 0.65$ & $98.93 \pm 0.51$ \\
\hline & Lef & Diclo & Lef & Diclo \\
\hline 0 & $100.7 \pm 0.707$ & $100.3 \pm 0.21$ & $101.04 \pm 0.58$ & $100.09 \pm 0.98$ \\
\hline $30^{*}$ & $103.36 \pm 0.51$ & $98.85 \pm 0.23$ & $102.25 \pm 0.31$ & $100.52 \pm 0.75$ \\
\hline $60^{* *+}$ & $110.41 \pm 0.58$ & $98.79 \pm 0.29$ & $103.25 \pm 0.22$ & $100.84 \pm 0.23$ \\
\hline $90^{* *+}$ & $112.95 \pm 0.19$ & $96.76 \pm 0.33$ & $104.3 \pm 0.54$ & $101.14 \pm 0.46$ \\
\hline $120^{* \star+}$ & $111.19 \pm 0.268$ & $96.77 \pm 0.403$ & $106.6 \pm 0.19$ & $100.84 \pm 0.15$ \\
\hline $150^{* *++}$ & $111.76 \pm 0.23$ & $96.91 \pm 0.321$ & $104.8 \pm 0.412$ & $101.69 \pm 0.28$ \\
\hline \multirow[t]{2}{*}{$180^{\star *++}$} & $108.05 \pm 0.71$ & $97.94 \pm 0.46$ & $105.86 \pm 0.313$ & $101.83 \pm 0.42$ \\
\hline & & & Lef & Mef \\
\hline 0 & - & - & $100.15 \pm 0.21$ & $100.08 \pm 0.268$ \\
\hline 30 & - & - & $101.75 \pm 0.35$ & $101.82 \pm 0.247$ \\
\hline
\end{tabular}


Citation: Sultana N, Arayne MS, Khan MM, Ali SN (2013) Development of Liquid Chromatography-UV Method for Simultaneous Determination of Leflunomide and NSAIDs in API and Pharmaceutical Formulations: It's Application to In vitro Interaction Studies. Med chem 3: $262-270$. doi:10.4172/2161-0444.1000149

\begin{tabular}{|c|c|c|c|c|}
\hline 60 & - & - & $100.65 \pm 0.49$ \\
\hline 90 & - & - & $100.69 \pm 0.43$ \\
\hline 120 & - & - & $100.42 \pm 0.82$ \\
\hline 150 & - & - & $100.79 \pm 0.49$ & $101.39 \pm 0.19$ \\
\hline $180^{*}$ & - & - & 10.65 & $102.7 \pm 0.42$ \\
\hline
\end{tabular}

Lef=leflunomide, Flur=flurbiprofen, Ibu=ibuprofen, Mef=mefanamic acid, Diclo=diclofenac sodium. * and ${ }^{* *}$ indicates $p<0.05$ (significant) and $p<0.005$ (highly significant)at $\mathrm{pH} 4$ while $^{+}$and $^{++}$indicates $\mathrm{p}<0.05$ (significant) and $\mathrm{p}<0.005$ (highly significant) interaction at $\mathrm{pH} 9$

Table 7: Interaction study of leflunomide with NSAIDs by proposed UV method.

\begin{tabular}{|c|c|c|c|c|}
\hline \multirow{2}{*}{ Time (mins) } & \multicolumn{2}{|c|}{ At pH $4 \%$ Availability (mean \pm S.D) } & \multicolumn{2}{|c|}{ At pH $9 \%$ Availability(mean \pm S.D) } \\
\hline & Lef & Flur & Lef & Flur \\
\hline 0 & $100.06 \pm 0.21$ & $99.99 \pm 0.27$ & $100.02 \pm 0.35$ & $100.06 \pm 0.09$ \\
\hline 30 & $100.5 \pm 0.42$ & $101.01 \pm 0.22$ & $98.04 \pm 0.61$ & $107.97 \pm 0.81$ \\
\hline $60^{*}$ & $100.72 \pm .51$ & $102.65 \pm 0.13$ & $102.4 \pm 0.51$ & $103.25 \pm 0.57$ \\
\hline $90^{*}$ & $99.89 \pm .13$ & $105.8 \pm 0.61$ & $100.12 \pm 0.43$ & $99.99 \pm 0.26$ \\
\hline $120^{\star *}$ & $98.33 \pm .71$ & $113.52 \pm 0.99$ & $102.14 \pm 0.76$ & $101.7 \pm 0.49$ \\
\hline $150^{* *+}$ & $96.38 \pm .19$ & $117.55 \pm 0.42$ & $104.28 \pm 0.27$ & $102.58 \pm 0.94$ \\
\hline \multirow[t]{2}{*}{$180^{* *++}$} & $93.38 \pm 18$ & $131.62 \pm 0.51$ & $99.86 \pm 0.772$ & $105.88 \pm 0.21$ \\
\hline & Lef & Ibu & Lef & Ibu \\
\hline 0 & $100.1 \pm 0.98$ & $100.01 \pm 0.74$ & $100.25 \pm 0.98$ & $99.97 \pm 0.11$ \\
\hline 30 & $97.98 \pm 0.510 .29$ & $98.15 \pm 0.26$ & $100.39 \pm 0.57$ & $98.04 \pm 0.52$ \\
\hline 60 & $98.09 \pm 0.34$ & $98.68 \pm 0.13$ & $104.18 \pm 0.64$ & $102.75 \pm 0.41$ \\
\hline $90^{*}$ & $99.031 \pm 0.32$ & $98.2 \pm 0.27$ & $104.09 \pm 0.26$ & $103.46 \pm 0.49$ \\
\hline $120^{*}$ & $103.33 \pm 0.23$ & $99.3 \pm 0.53$ & $103.53 \pm 0.94$ & $102.91 \pm 0.75$ \\
\hline $150^{* \star++}$ & $101.35 \pm 0.24$ & $97.9 \pm 0.49$ & $105.89 \pm 0.25$ & $103.07 \pm 0.64$ \\
\hline \multirow[t]{2}{*}{$180^{* *++}$} & $103.64 \pm 0.19$ & $96.6 \pm 0.21$ & $108.69 \pm 0.16$ & $104.74 \pm 0.28$ \\
\hline & Lef & Diclo & Lef & Diclo \\
\hline 0 & $100.1 \pm 0.23$ & $100.15 \pm 0.74$ & $100.02 \pm 0.64$ & $99.99 \pm 0.51$ \\
\hline $30^{*}$ & $101.33 \pm 0.54$ & $104.9 \pm 0.16$ & $99.89 \pm 0.91$ & $99.29 \pm 0.42$ \\
\hline $60^{* *+}$ & $102.16 \pm 0.86$ & $110.11 \pm 0.98$ & $99.29 \pm 0.83$ & $95.60 \pm 0.26$ \\
\hline $90^{* *+}$ & $101.4 \pm 0.64$ & $111.85 \pm 0.23$ & $102.79 \pm 0.43$ & $105.78 \pm 0.54$ \\
\hline $120^{* *+}$ & $107.25 \pm 0.35$ & $110.15 \pm 0.34$ & $99.89 \pm 0.71$ & $97.65 \pm 0.19$ \\
\hline $150^{* \star++}$ & $110.19 \pm 0.46$ & $125.2 \pm 0.56$ & $102.46 \pm 0.43$ & $99.04 \pm 0.18$ \\
\hline \multirow[t]{2}{*}{$180^{* \star++}$} & $112.12 \pm 0.28$ & $126.67 \pm 0.47$ & $105.23 \pm 0.22$ & $101.58 \pm 0.29$ \\
\hline & & & Lef & Mef \\
\hline 0 & - & - & $100.91 \pm 0.23$ & $100.04 \pm 0.43$ \\
\hline 30 & - & - & $100.7 \pm 0.52$ & $100.65 \pm 0.61$ \\
\hline 60 & - & - & $100.61 \pm 0.16$ & $100.01 \pm 0.78$ \\
\hline 90 & - & - & $101.13 \pm 0.14$ & $101.27 \pm 0.98$ \\
\hline 120 & - & - & $101.51 \pm 0.09$ & $100.27 \pm 0.15$ \\
\hline 150 & - & - & $101.99 \pm 0.21$ & $102.05 \pm 0.11$ \\
\hline $180^{*}$ & - & - & $102.78 \pm 0.84$ & $101.99 \pm 0.31$ \\
\hline
\end{tabular}

Lef=leflunomide, Flur=flurbiprofen, Ibu=ibuprofen, Mef=mefanamic acid, Diclo=diclofenac sodium. * and ${ }^{* *}$ indicates $p<0.05$ (significant) and $p<0.005$ (highly significant)at $\mathrm{pH} 4$ while ${ }^{+}$and ${ }^{++}$indicates $\mathrm{p}<0.05$ (significant) and $\mathrm{p}<0.005$ (highly significant) interaction at $\mathrm{pH} 9$

Table 8: Interaction study of leflunomide with NSAIDs by proposed RP- HPLC method.

interaction was insignificant $(\mathrm{p}>0.05)$ except at 180 minutes $(\mathrm{p}=0.023)$ which was significant $(\mathrm{p}<0.05)$ (Table 8$)$.

\section{Conclusion}

A facile reversed-phase HPLC-UV method for the simultaneous determination of leflunomide, flurbiprofen, ibuprofen, diclofenac sodium and mefenamic acid been developed for the first time. In addition to its novelty for simultaneously determining four NSAIDs with lefunomide in two different phases and using two different columns the method is sufficiently rapid, simple, sensitive as well as precise and accurate that complies with ICH guidelines [19] for accuracy, precision and stability for standards and QC samples. The detector response was found to be linear over a wide concentration range having LLOD for flurbiprofen, ibuprofen, diclofenac sodium and mefenamic acid 6.9, 296, 71 and $12 \mu \mathrm{g} \mathrm{mL}^{-1}$ respectively. No interference of extra pharmaceutical ingredients was observed in the assay and was successfully applied in raw materials and pharmaceutical formulations. The main advantage of the proposed analytical method is the use of the same mobile phase for the determination leflunomide and NSAIDs in bulk and in dosages formulations. Hence, it can be recommended for the routine quality control of these drugs. In addition to the analysis of these drugs, this rapid and reproducible analytical method is suitable for dissolution studies and can also be used for routine clinical, pharmacokinetic and interaction studies conducted in humans as they are prescribed simultaneously to patients of rheumatoid arthritis.

The developed method has been applied to study in vitro interactions between lefunomide and flurbiprofen, ibuprofen, diclofenac sodium and mefenamic acid in simulated human body environments. The results of interaction studies showed that activity of leflunomide may be affected in presence of NSAIDs when given simultaneously. In this in vitro studies, it is observed that flurbiprofen, ibuprofen and diclofenac sodium affect leflunomide's availability in a 
Citation: Sultana N, Arayne MS, Khan MM, Ali SN (2013) Development of Liquid Chromatography-UV Method for Simultaneous Determination of Leflunomide and NSAIDs in API and Pharmaceutical Formulations: It's Application to In vitro Interaction Studies. Med chem 3: $262-270$. doi:10.4172/2161-0444.1000149
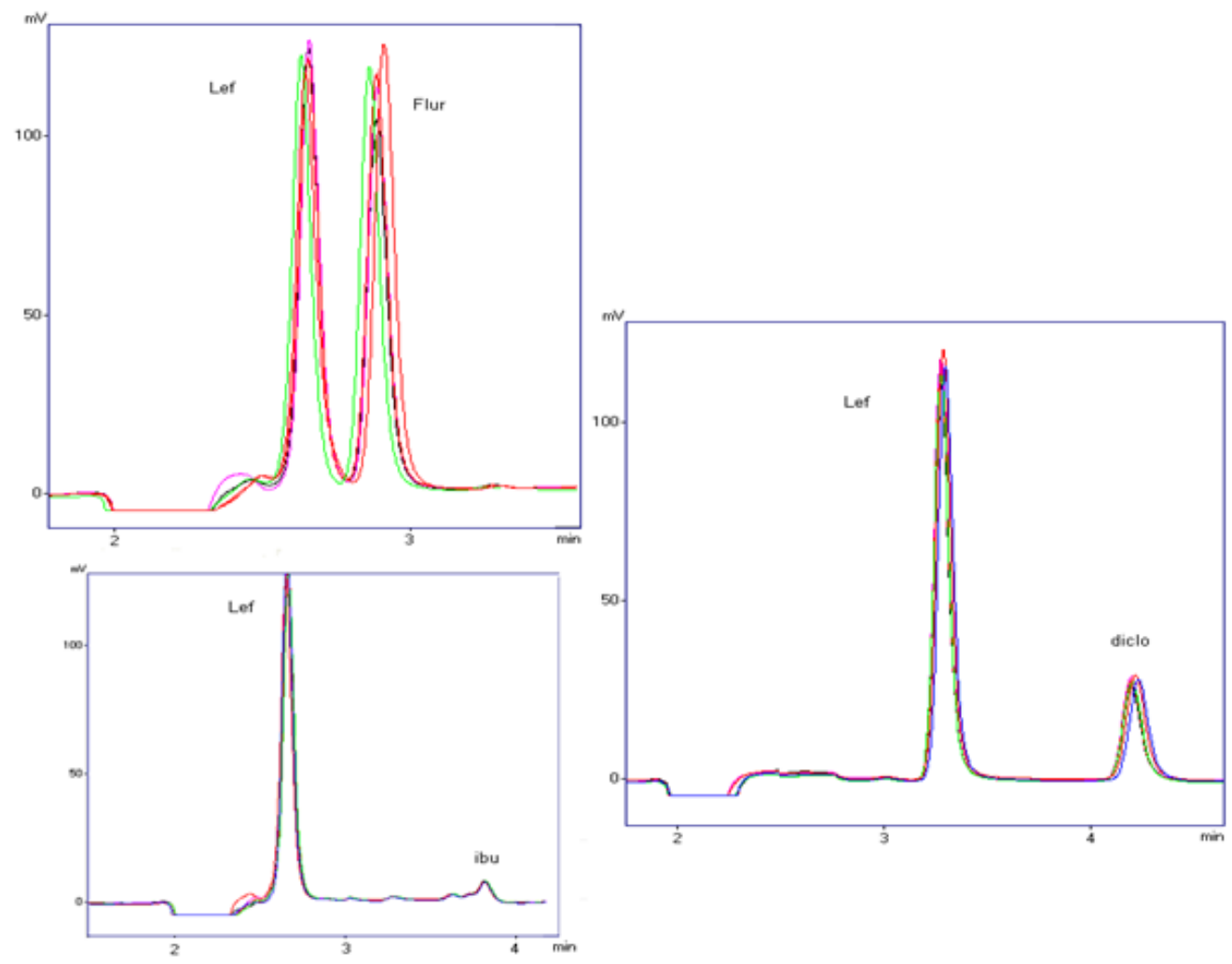

Figure 5a: Drug interacting chromatograms of leflunomide and NSAIDs at $\mathrm{pH} 4$
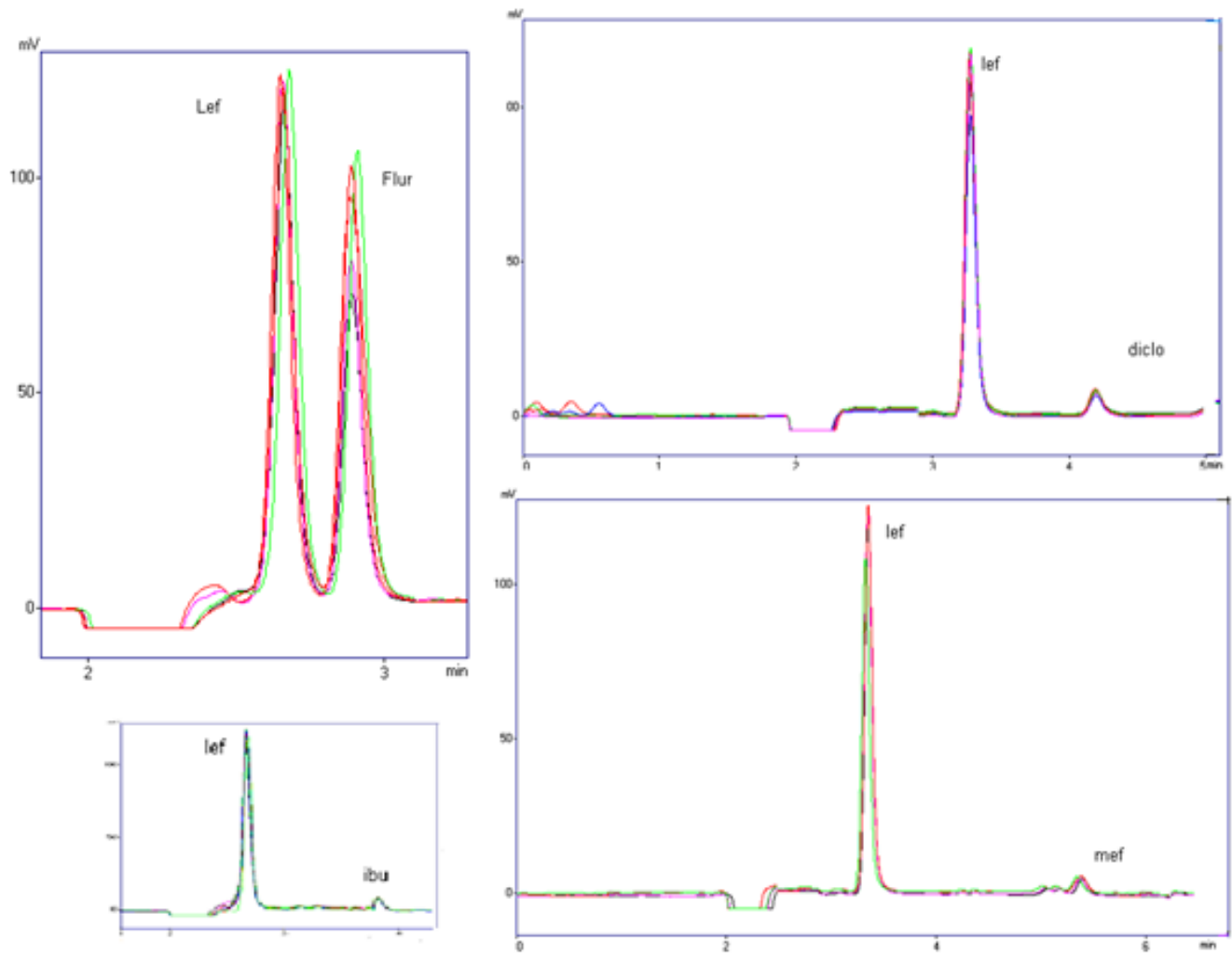

Figure 5b: Drug interacting chromatograms of leflunomide and NSAIDs at $\mathrm{pH} 9$ 
Citation: Sultana N, Arayne MS, Khan MM, Ali SN (2013) Development of Liquid Chromatography-UV Method for Simultaneous Determination of Leflunomide and NSAIDs in API and Pharmaceutical Formulations: It's Application to In vitro Interaction Studies. Med chem 3: $262-270$. doi:10.4172/2161-0444.1000149

highly significant $(\mathrm{p}<0.005)$ manner as compared to mefenamic acid however there in vivo detailed interaction should be studied in future.

\section{References}

1. Jones PBB, White DHN (2010) Reappraisal of the clinical use of leflunomide in rheumatoid arthritis and psoriatic arthritis. Open Access Rheumatol Res Rev 2: 53-71.

2. Gummert JF, Ikonen T, Morris RE (1999) Newer Immunosuppressive drugs A Review. J Amer Soc Nephrol 10:1366-1380.

3. Breedveld FC, Dayer JM (2000) Leflunomide: mode of action in the treatment of rheumatoid arthritis. Annals of the rheumatic diseases 59:841-849.

4. Chong AS, Finnegan A, Jiang X, Gebel H, Sankary HN, et al. (1993) Leflunomide, a novel immunosuppressive agent. The mechanism of inhibition of T cell proliferation. Transplantation 55:1361-1366.

5. Cherwinski HM, Cohn RG, Cheung P, Webster DJ, Xu YZ, et al. (1995) The immunosuppressant leflunomide inhibits lymphocyte proliferation by inhibiting pyrimidine biosynthesis. Journal of Pharmacology and Experimental Therapeutics 275:1043-1049.

6. Jaegle SS, Williamson RA, Yea CM, Robson PA, Curnock AP and Adher S (1996) Dihydroorotate dehydrogenase is a target for the biological effects of leflunomide. Transplant Proc 28:3088-3091.

7. Williamson RA, Yea CM, Robson PA, Curnock AP, Gadher S, et al. (1995) Dihydroorotate dehydrogenase is a high affinity binding protein for A77 1726 and mediator of a range of biological effects of the immunomodulatory compound. J Biol Chem 270: 22467-22472.

8. Axton CA, Billingham MEJ, Bishop PM, Gallagher PT, Hicks TA, et al. (1992) Novel immunosuppressive butenamides. J Chem Soc, Perkin Transaction (London) 1: 2203-2213.

9. Kuo EA, Hambleton PT, Kay DP, Evans PL, Matharu SS, et al. (1996) Synthesis, structure-activity relationships, and pharmacokinetic properties of dihydroorotate dehydrogenase inhibitors: 2-cyno-3-cyclopropyl-3-hydroxy-N[3'-methyl-4'-(trifluoromethyl)phenyl]propenamide and related compounds. J Med Chem 39: 4608-4621.

10. Albers JMC, Paimela L, Kurki P (2001) Treatment strategy, disease activity, and outcome in four cohorts of patients with early rheumatoid arthritis. Ann Rheum Dis 60:453-458

11. Harvey RA. Lippincott's illustrated reviews: Pharmacology (4th international Ed.). 2005 Unit VIII, Anti-inflammatory Drugs and Autocoids, Anti-inflammatory Drugs 499-519.

12. Duygu Y, Dilek DA, Muzaffer T (2006) Determination of leflunomide in tablets by high performance liquid chromatography. J Pharm Biomed Anal 40:197-201.

13. Miron DS, Soldattelli C, Schapoval EES (2006) HPLC with diode-array detection for determination of leflunomide in tablets. Chromatographia. 63: 283-287.

14. Chan V, Charles BG, Tett SE (2004) Rapid determination of the active leflunomide metabolite A77 1726 in human plasma by high-performance liquid chromatography. J Chromatogr B Anal Technol Biomed Life Sci 803:331-335.

15. Pawinski T, Gralak B (2005) HPLC determination of active metabolite of leflunomide in plasma. Chem Anal 50: 785-793.

16. Schmidt A, Schwind B, Gillich M, Brune K, Hinz B (2003) Simultaneous determination of leflunomide and its active metabolite, A77 1726, in human plasma by high-performance liquid chromatography. Biomed Chromatogr 17 : 276-281.

17. Sultana N, Arayne MS, Khan MM, Mohammed N (2011) Development and validation of a liquid chromatographic method for the determination of leflunomide: Application to in vitro drug metal interactions Chin J Chem 29: 1933-1938.

18. Panusa A, Multari G, Incarnato G, Gagliardi L (2007) High-performance liquid chromatography analysis of anti-inflammatory pharmaceuticals with ultraviolet and electrospray-mass spectrometry detection in suspected counterfeit homeopathic medicinal products. J Pharm Biomed Anal 43: 1221-1227.

19. Arayne MS, Sultana N, Tabassum A, Ali SN, Safila Naveed S (2012) simultaneous determination of rosuvastatin, lisinopril, captopril and enalapril in API, formulations and human serum by liquid chromatography. Med Chem Res 21: 4542-4548.

20. Sultana N, Arayne MS, Siddiqui R, Naveed S (2012) RP-HPLC method for the simultaneous determination of lisinopril and NSAIDs in API, pharmaceutical formulations and human serum. Amer J Anal Chem 3:147-152.
21. Sultana N, Arayne MS, Waheed A (2011) Method development of verapamil in presence of NSAIDs using RP-HPLC Technique. Bull Korean Chem Soc 32: $2274-2278$

22. Sultana N, Arayne MS, Naveed S (2010) Simultaneous quantitation of captopril and NSAIDs in API, dosage formulations and human serum by RP-HPLC. J Chin Chem Soc 57: 62-67.

23. Sultana N, Arayne MS, Shehzad W (2010) Simultaneous determination of ceftriaxone sodium and non steroidal anti-inflammatory drugs in pharmaceutical formulations and human serum by RP-HPLC. J Chin Chem Soc 57: 1278-1285.

24. Sultana N, Arayne MS, Shafi N, Siddiqui F (2010) Simultaneous RP-LC analysis of diltiazem and non-steroidal anti-Inflammatory drugs in pharmaceutical formulations and human serum. Chromatogr 71:71-77.

25. Sultana N, Arayne MS, Tabassum A (2012) Simultaneous quantitation and monitoring of rosuvastatin with NSAIDs by liquid chromatography with UVdetection. Res Reports Med Chem 2:19-29.

26. Gul S, Sultana N, Arayne MS, Shamim S, Akhtar M (2012) New method for optimization and simultaneous determination of sparfloxacin and non steroidal anti-inflammatory drugs: Its in-vitro application. Amer J Anal Chem 3:328-337.

27. Arayne MS, hahnaz H, Haider A, Sultana N (2013) Carboxyterfenadine antacid interaction monitoring by UV spectrophotometry and RP-HPLC techniques. Arabian J Chem

28. Arayne MS, Nawaz M, Sultana N (2012) Drug interactions and synthesis of cefpirome with hypoglycemic agents. Med Chem.

29. Arayne MS, Sultana N, Sherbhadur S, Nawaz M (2012) Simultaneous determination of amlodipine with $\mathrm{H} 1$-receptor antagonists by reversed phase high performance liquid chromatography and application to interaction studies Amer J Anal Chem 3:631-636.

30. Arayne MS, Nawaz M, Sultana N (2011) Monitoring of cefpirome-antioxidant interaction studies by RP-HPLC Medicinal Chemistry Research Research 21, 2181-2184.

31. Arayne MS, Sultana N, Zuberi H, Haroon U (2010) In vitro studies of interaction between metformin and NSAIDs (non steroidal anti-inflamatory drugs) using spectrophotometry and rp-high performance liquid chromatography Journal of Chilean Chemical Society 55: 206-211

32. Arayne MS, Sultana N, Shamshad H, Mirza AZ (2010) Drug interaction studies of gliquidone with fexofenadine, cetirizine and levocetirizine. Med Chem Res 19: $1064-1073$.

33. Arayne MS, Sultana N, Haroon U, Zaidi B (2009) In vitro evidences for simvastatin and losartan potassium interaction and its in vivo implications $\mathrm{J}$ Chil Chem Soc 54: 432-436.

34. Arayne MS, Sultana N, Rizvi SBS, Haroon U (2009) In vitro drug interaction studies of atorvastatin with ciprofloxacin, gatifloxacin, and ofloxacin. Med Chem Res 19: 717-731

35. Sultana N, Naveed S, Arayne MS (2013) Monitoring of in vitro interaction studies of enalapril with hypoglycemic agents by LC-UV. Res Rep Med Chem 3: $1-7$

36. Sultana N, Arayne MS, Ali SN (2012) Ultra-sensitive LC method for the simultaneous determination of paracetamol, carbamazepine, losartan and ciprofloxacin in bulk drug, pharmaceutical formulation and human serum by programming the detector. Amer J Anal Chem 4:24-33.

37. Sultana N, Arayne MS, Ali SN (2012) An ultra-sensitive LC method for simultaneous determination of rosuvastatin, alprazolam and diclofenac sodium in API, pharmaceutical formulations and human serum by programming the detector. J Anal Bioanal Techniques 3:154.

38. Sultana N, Arayne MS, Mohd N, Rehman Z (2011) Liquid chromatographic analysis of halofantrine from dosage form and its metal interaction studies. Med Chem Res 20:531-534

39. Sultana N, Arayne MS, Gul S, Akhtar M, Shamim S (2011) Simultaneous determination of sparfloxacin and commonly used $\mathrm{H}_{2}$ receptor antagonists by RP-HPLC: Application to in-vitro drug interactions. Med Chem Res 21: $974-$ 982.

40. Sultana N, Hamza E, Arayne MS, Haroon U (2011) Effect of metal ions on the in vitro availability of enoxacin, its in vivo implications, kinetic and antibacterial studies. Quim Nova 34:186-189. 